\title{
Protection and Renewal of Traditional Villages in Jiangxi Province under the Background of Rural Revitalization- Taking Futang Village as an Example
}

\author{
Liping $\mathrm{Li}^{1}{ }^{1}$, Jinlong $H u^{1, *}$,Yaobao Teng ${ }^{1}$ \\ ${ }^{1}$ College of Tourism\&landscape Architecture, Guilin University of Technology, Guilin 541006, China
}

\begin{abstract}
Traditional villages have condensed countless material and spiritual civilizations which have been created by Chinese working people to adapt to the living environment since ancient times. With the strategy of rural revitalization, the ancient traditional villages need urgent attention for rebirth. Via literature review and on-site inspection, this paper summarizes and analyses the general protection and renewal status of national traditional villages in Jiangxi Province, and takes Futang Village as an example for further explanation. Based on the general status, four suggestions are put forward to make sure that the Jiangxi's traditional villages and cultures can get real protection and long-term development during the construction and revitalization.
\end{abstract}

\section{Preface}

The rural revitalization strategy has been the top priority in the national work in recent years. Unlike ordinary ones, traditional villages which was formed earlier, and preserved more completely, have certain historical, cultural, scientific, artistic, economic and social value ${ }^{[1]}$, become the carrier of Chinese rural material and spiritual civilization $^{[2]}$ and the important support of cultural self-confidence. These characteristics make them have a more special position in rural revitalization. After the reform and opening up, the rapid development of industrialization and urbanization has greatly impacted thousands of years of farming civilization, and the traditional villages have begun to disappear in large numbers ${ }^{[3]}$. In 2011, China's rural population accounted for $48.7 \%$ of the total population, for the first time below the urban population, foreshadowing an unprecedented era of cultural heritage. And there is a serious regional imbalance in the Chinese development. Jiangxi, as old revolutionary area and multi-cultural region with backward economy and many traditional villages, has carried out the protection and renewal of traditional villages these years, which is worthy of further study.

\section{Background overview}

\subsection{The strategy of rural revitalization}

At the 19th Communist Party of China National Congress in 2017, Xi Jingping put forward the strategy of rural revitalization to speed up the modernization of agriculture and rural areas. And the No.1 Center Documents of 2018 and 2019 were both closely related to the strategy of rural revitalization. In September 2018, the State Council issued The Strategic Plan for Rural Revitalization (2018-2022), which comprehensively discussed the planning direction and put forward the strategic objectives of promoting the revitalization of rural industries, building ecologically livable beautiful villages, prospering and developing rural culture, perfecting the modern rural governance system and ensuring and improving rural people's livelihood. According to the schedule of the strategy, the correlative institutional framework and policy system will be basically formed in 2020 and preliminarily built in 2022, the agricultural rural modernization will be basically realized by 2035 , and in 2050 the rural areas will be fully revitalized with strong agriculture, beautiful rural and wealthy farmer ${ }^{[4]}$. At present, the first stage of rural revitalization strategies has been carried out halfway, and the face of the country's villages has greatly improved. However, because the early focus was on overcoming poverty, the villages are eager to choose some industries to escape poverty, and ignore some other aspects. For example, some traditional village protection and renewal did not really work.

\subsection{Current situation of traditional villages in Jiangxi Province}

In 2012, the Ministry of Housing and Urban-Rural Development and other three departments started the investigation of traditional villages in the country. There have been 6819 national traditional villages selected so far, some of which can receive support fund of 3 million yuan provided by the central government, mainly for repairing traditional buildings and historical relics, and improving public infrastructure, etc ${ }^{[5]}$. 
Jiangxi is a key area for poverty alleviation, gathering the architectural style of Hui, Gan and Hakka. It has 343 national traditional villages, accounting for $5.03 \%$ of the country, mainly concentrated in Fuzhou, Ji'an, Ganzhou, Shangrao, etc. There are mainly mountains, hills and basins, and are less industrial impact, so traditional civilization remains relatively complete. Lots of field surveys on traditional villages in Jiangxi Province in 2019 found that the whole rural appearance has improved significantly, but there are still some problems.

\subsubsection{Inadequate protection}

It should be handed over to professional people to protect traditions, and most villages have no reasonable industrial planning. Jiangxi is a traditional agricultural province with backward economy and weak education. It is difficult to fully analyze the suitable development path of villages only by the local township governments and villagers. And the real traditions might be further lost in the process of the infrastructure construction. Besides practical measures, perfect acceptance check is also required for better protection. In Jiangxi, the awareness of protecting traditional culture is still weak, the relevant laws and regulations are not sound, and the real reasonable protection is limited. As a result of these, after the protection and renewal, there will be many loopholes and regrets.

\subsubsection{Lack of beauty in landscape}

Jiangxi's traditional villages take agricultural landscape as background and quaint buildings as framework, which and the texture of lanes derive landscape beauty. The rural landscape is more approaching to life and has a strong agricultural flavor, which is just like the scattered rubble on the ridge, the disordered grass along the roadside, pesticide package wastes on the edge of the field, the women washing clothes and vegetables by the pond, the peanuts put on the open ground in front of houses and so on. The nature of the countryside determines that the rural space must be given priority to production rather than the beauty of landscape, which is latter demand after production under the backward economic environment, so that the level of most Chinese rural landscape is low. Rural modernization is required by the strategy, and Jiangxi government has also called for building beautiful countryside. We can see that the countryside will become beautiful and ecological is the general trend and the necessary prerequisite to improve the quality of farmers' life.

\subsubsection{Lack of Facilities}

In recent years, since more and more young rural people have left for big cities, some phenomena like hollow villages, left-behind children and the elderly are serious. Regardless of the appearance, the lack of healthy and sustainable industrial planning and perfect infrastructure system in the village is the focus. To protect traditional villages better, it is necessary to consider the basic needs of rural people, especially the infrastructure which includes transportation, hydropower network, sewage discharge, communication systems, etc. Most villages are not sound due to economic backwardness, such as public transportation system, public parking lot, piped water system, and supporting medical, commercial and logistics services in residential areas. Insufficient imperfect facilities lead inconvenient life and limit rural development.

\subsubsection{Lack of Vitality in Culture}

The Hui, Gan and Hakka cultures in Jiangxi are rooted in life and gather in traditional villages, which condenses the survival wisdom that man and nature coexist in harmony and has a high degree of compatibility with local natural environment and villagers ${ }^{[8]}$. However, before fully understanding the advantages and forming enough cultural confidence, most people wavered in the traditional wisdom and gave up their own characteristics under the great impact of foreign cultures, so there are cement brick buildings, western-style doors, windows and railings and so forth in many villages. Copying the outside cultures is just like wearing the ill-fitting clothes, which makes it uncomfortable and invigorating.

\section{Renewal of traditional villages in Jiangxi Province -- Taking the Futang Village as an example}

\subsection{Overview of Futang Village}

The Futang Village, belongs to Liufang Village Hutang Town Fengcheng City, located in the middle of Jiangxi Province and the southern end of Poyang Lake Basin, with relatively flat terrain. It is close to the Wenquan Road, $3 \mathrm{~km}$ away from the Fengcheng entrance and exit of Shanghai Kunming Expressway, 56km away from the center of Nanchang, so the village location is convenient. It is close to Yichun's first national 4A tourism attraction, the town of Chinese Love Flowers. There are 386 people in Futang Village, with the construction area of $16746 \mathrm{~m}^{2}$ and cultivated land area over 800 acres, where mainly plants selenium-rich rice, watermelon, peanut and rape.

Futang Village has been built for more than 700 years. Up to now, the texture and traditional features have remained relatively complete. The stand-alone and single-storey residential houses are mainly in Gan style, built with black bricks, grey tiles and Ma Tau walls, and loaded with wooden components. The front doors are facing the west and rear doors to the east. The front of the house is the hall with a narrow patio or glass skylight for lighting and ventilation, and the back is the kitchen. The sculpture decoration of brick, wood and stone is beautiful, especially on the doors and high windows. Villagers are used to drawing water from wells and often several households share one well. Most public buildings were reconstructed in modern times, such as the archway, ancestral temple, tourist service center, water retaining dam, etc. The only surname in Futang Village is Li and 
according to the Li's Genealogy in ancestral temple, the ancestors moved from Fuzhou in Jiangxi to Lifang in Jianxi during the Southern Song Dynasty and from Chikeng to this place in the Yuan Dynasty. Since there were surrounded by hills and rivers the ancestors named it Futang, which means full of resources. In the late Qing Dynasty, one villager Li Zhiyuan made a fortune by business of gold and silver ornaments in Hunan, and led other villagers to go out to engage in gold and silver processing business. So in addition to agriculture and architectural culture, there are also the handicraft and business culture in Futang Village. After being rich, Li Zhiyuan invested enormously in building the temple and ancestral hall, paving lanes and planting lotus for his home town, most of which have remained to this day[9]. With these unique buildings and cultures, Futang Village has become one of the first pilot villages for beautiful rural construction in Fengcheng, and been selected into the Jiangxi Province's traditional villages and the fifth batch of national traditional villages in 2017 and 2018, getting the national financial subsidies ${ }^{[10]}$.

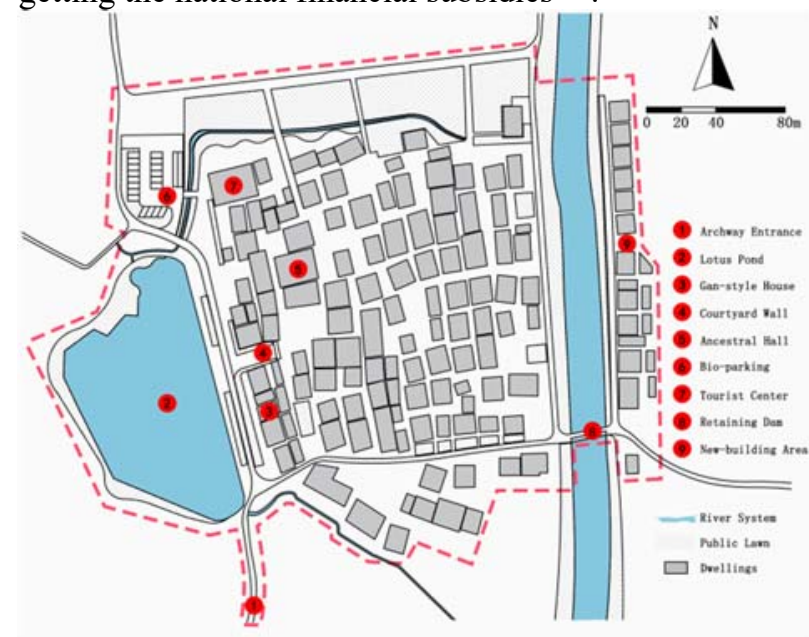

Fig. 1. Futang Village plan.

\subsection{Renewal status of Futang Village}

Hutang Township planned to carry out the rural cultural landscape development and beautiful rural construction at the same time in order to comprehensively improve the rural human settlement environment. In 2018, Futang Village responded to the call for the beautiful rural construction and started village landscape renovation and infrastructure improvement.

\subsubsection{Homestead Management}

Reasonable spatial planning is conducive to efficient utilization. Futang Village's reconstruction and renewal began with homestead management. After the house area statistics and public announcement in the early stage, the village committee held a mass meeting, and determined each family's housing area according to the principle of 'one family, one house". The vacant annexes were removed up to $2000 \mathrm{~m}^{2}$, the collapsed houses were rebuilt or replaced by distributing new spaces, the houses by the main street or near the public space were repaired by whiting and painting the exterior walls, and the scattered cattle and pig pens were centralized resettled to remove odors from livestock. The overall village gets more humanization, and looks neat and orderly.

\subsubsection{Landscape reconstruction}

In terms of landscape, the entrance archway is refreshed, combining cherry blossoms and asphalt road to give a new impression of ancient rhyme. The lotus pond in front of the residential area and the landscape around have greatly improved the village's landscape quality. The pavement of lanes and virescence of the opening space have added many points to the landscape, and the overall style are quite appropriate to the temperament of the village. However, there are still some aspects to be improved, such as that the practice of the wall painting doesn't match the traditional village style, the water pollution caused by rubbish in the east river is serious and need to be treated, and the farmland landscape around residential houses as the big background of the village environment can be further improved.

\subsubsection{Infrastructure construction}

As for infrastructure, solar energy-saving street lamps are installed on the main road, and the night is no longer too dark to go outside without flashlights. The lanes are covered with black bricks, easy to walk, and sewer pipes are laid down the lanes to facilitate the installation of toilets in village homes. New public toilet is built next to tourist centre. The water quality of the canals around the village is significantly improved by renovating and dredging, and the sound of flowing water activates the atmosphere. The new parking lot is planned for peak parking on holidays. Garbage bins are set up in front of each household, and the paintings on the walls guide villagers to sort the garbage. Via the infrastructure construction, the improvement of the living environment in the village is very significant, and the villagers' sense of contentment and happiness is stronger.

\subsubsection{Protection of Traditional Culture}

In terms of traditional culture, the red and blue tones of the renovated archway create a classical atmosphere. Beside the main entrance of the village, there put some landscape display boards about family instructions and village regulations. An old two-yard house, built in the Republic of China and in typical Gan style, has been repaired according to the original appearance. And in the exhibition hall of village history, there are old farming tools and living supplies on display, such as plows, textile machines, bamboo tobacco pipe, kerosene lamp and so on. Some exterior walls of dwellings are painted with poems and paintings in praise of countryside life. To enrich its traditional culture, Futang Village borrows the Zhuangyuan stories from Hutang Township, and Shehuo from Fengcheng for publicity. Comparing with the surrounding villages, Futang's cultural protection practices are very similar to theirs, which leads to that 
the villages look the same. If we excavate characteristic culture too shallow, internally it's hard to establish the villagers' cultural confidence, and externally the village seems lacking in its own features.

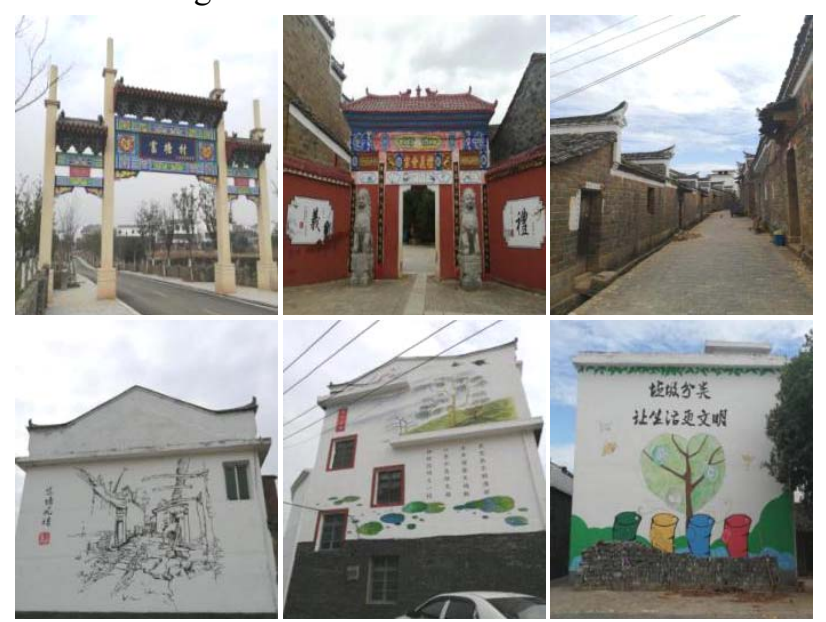

Fig. 2. Updated views of Futang Village.

\subsection{Suggestions for the renewal of traditional villages}

\subsubsection{Sustainable industrial planning}

Because of the different spatial scales, the development of rural industry can not copy the city, so it is necessary to choose the industry which is suitable for the local background and conditions in order to achieve further development. Traditional villages always take traditional agriculture as their main industry, but under the call of the state, rural tourism has become the preferred new industry. Futang Village can develop unique tourism products based on the background of its own buildings and handicraft industry and commerce cultural, and furthermore join hands with the 4A tourist attraction nearby to develop characteristic tourism.

\subsubsection{Scenic country landscape}

The construction of beautiful countryside in Jiangxi has initially improved the rural appearance, but the landscape is not enough. According to our survey, due to the limited design ability and fund, the government collected and promoted nearly 60 traditional village house design schemes in 2016, and more than $60 \%$ of the traditional villages choose to use them directly in 2017, which leads to similar situations in many villages, for example,the white and painted houses. It is suggested that the government take the lead to introduce and invite professional teachers and students from universities and design practitioners to participate in the renewal design of rural landscape, and continue to excavate and seek more local cultural features and landscape styles.

\subsubsection{More convenient living facilities}

Improving living facilities is one of the most direct ways to improve the quality of rural life. However, most of the village planning only takes into account recent hardware improvements and does not combine the industrial planning and consider the longer-term and higher-level needs. Because of the special scope limit, some living service facilities, can not only supply a single village, such as education, medical services, modern logistics, convenient public transportation and so on. Therefore, the facility planning needs to step out of the village scale and joint townships or surrounding villages to plan together about the large living facility system.

\subsubsection{Vitalizing traditional cultures}

Among the ancient village cultures in Jiangxi Province, there are mainly three types, Gan style in the middle, Hui style in the north, and Hakka in the south. Like Futang Village, located in the middle of Jiangxi, has typical Gan cultural characteristics in the architectural forms, village layout, and folk customs. Villages are bound to flourish, but what will they flourish by? The answer is in tradition and innovation, which means the tradition should be renewed organically with the times, and we should combine with its own cultural and historical value, explore from the remains of buildings, summarize from ancient books like genealogy, and excavate from the folk features to find out the unique local traditional context. Later, reintegrate with modern technology to create a new kind of culture with modern form and traditional connotation.

\section{Summary and discussion}

China is in the crucial stage of building a society of initial prosperity in all respects, and the key to this period is the rural revitalization. For traditional villages, tourism is indeed the best industrial plan, which will not only cause little ecological damage, but also promote traditional culture. However, if all traditional villages choose this road, then the market competition will be fierce, such as a non-legacy with many nominal villages and the whole county involved, and blind profit-seeking development that leads to the villages like nothing. At that time, the protection of traditional villages will be more difficult ${ }^{[9]}$. A lot of facts have proved that only one industry can't last for a long time. When traditional villages take the road of tourism, they could also try to develop other related industries, such as the agricultural science and technology industry, cultural and creative industry, pension industry and so on.

How to properly protect and renew the precious traditional villages requires multi-disciplinary scholars to work together for advice, and the more social attention, the more opportunities and innovation. Futang Village is just an ordinary example, but it could illustrate many problems. If the planning is not professional enough and the consideration is not comprehensive and long-term enough, the village's look has been improved apparently, but the core traditional culture is still neglected and forgotten, and the renewal has become following the new and fashion. I hope to use this example as a guide to stimulate more thoughts. 


\section{Acknowledgements}

The acknowledgements should be given to the villagers and secretary of Futang Village for many times interviews. Thank the National Natural Science Fund of China (No. 31960252, 51968012) for the financial support.

\section{References}

1. Y. Hu, S. Chen, W. Cao, C.Z. Cao. The Concept and Cultural Connotation of Traditional Villages[J]. Urban Development Studies, 2014,21(01):10-13.

2. H.F. He, K. Zheng, S.M. Ni, H.R. Leng. Research Summary and Prospect of Ancient Villages in Jiangxi Province in Recent 20 Years[J]. Urban Development Studies, 2019,26(04):26-32.

3. J.C. Feng. The Dilemma and Outlet of Traditional Villages_-Also Discuss that Traditional Villages are another kind of cultural heritage[J]. Folk Culture Forum, 2013,No.218,9-14.

4. J.H. Liao. Protection and Development of Traditional Villages in the Vision of Rural Revitalization[J]. Reform, 2018,(04):130-139.

5. X. Gao, J.J. Li. Traditional Village Protection: Practical Difficulties and Institutional Defects[J]. Journal of South China Agricultural University (Social Sciences Edition), 2019,18(05):130-140.

6. X.Y. Wei, J.H. Cai, C.Q. Liu. Analysis of Type and Characteristic of Spatial Distribution of Traditional Village in Jiangxi Province[J]. Modern Urban Research, 2017,(08):39-44.

7. X.T. Fei. Earthbound China[M]. Jiangsu Phoenix Literature and Art Publishing: Nanjing, China, 2017.

8. H. Ma. Persistence and Transformation of Chinese Traditional Villages_- Rethinking the Planning of Traditional Settlements[J]. Urban Planning Forum, 2006,106-111.

9. H.S. Liang. Selection and Protection of Chinese Traditional Villages and Preliminary Study on Jiangxi's Present State[J]. Agricultural Archaeology, 2015, No.142,308-317.

10. Circular of the Ministry of Housing and Urban-Rural Development and Other Departments on the Announcement of the List of Chinese Traditional Villages Included in the Scope of Central Financial Support in 2018 [EB/OL]. Construction Department Official Website, http://www.mohurd.gov.cn/wjfb/201805/t20180511 _236024.html 